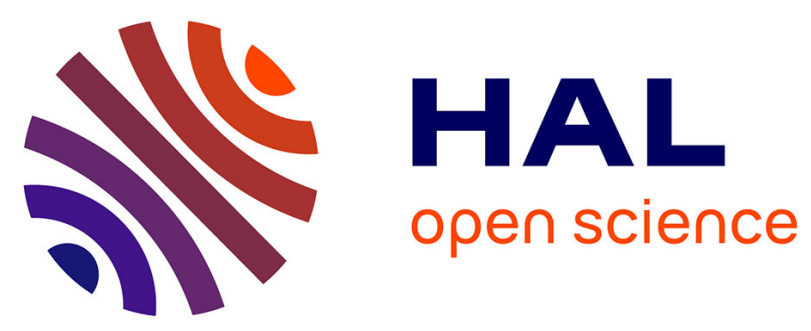

\title{
Characterization of the local Electrical Properties of Electrical Machine Parts with non-Trivial Geometry
}

Laure Arbenz, Abdelkader Benabou, Stéphane Clenet, Jean Claude Mipo, Pierre Faverolle

\section{- To cite this version:}

Laure Arbenz, Abdelkader Benabou, Stéphane Clenet, Jean Claude Mipo, Pierre Faverolle. Characterization of the local Electrical Properties of Electrical Machine Parts with non-Trivial Geometry. International Journal of Applied Electromagnetics and Mechanics, 2015, 48 (2\&3), pp.201-206. 10.3233/JAE-151988 . hal-01187422

\author{
HAL Id: hal-01187422 \\ https://hal.science/hal-01187422
}

Submitted on 13 Feb 2017

HAL is a multi-disciplinary open access archive for the deposit and dissemination of scientific research documents, whether they are published or not. The documents may come from teaching and research institutions in France or abroad, or from public or private research centers.
L'archive ouverte pluridisciplinaire HAL, est destinée au dépôt et à la diffusion de documents scientifiques de niveau recherche, publiés ou non, émanant des établissements d'enseignement et de recherche français ou étrangers, des laboratoires publics ou privés. 


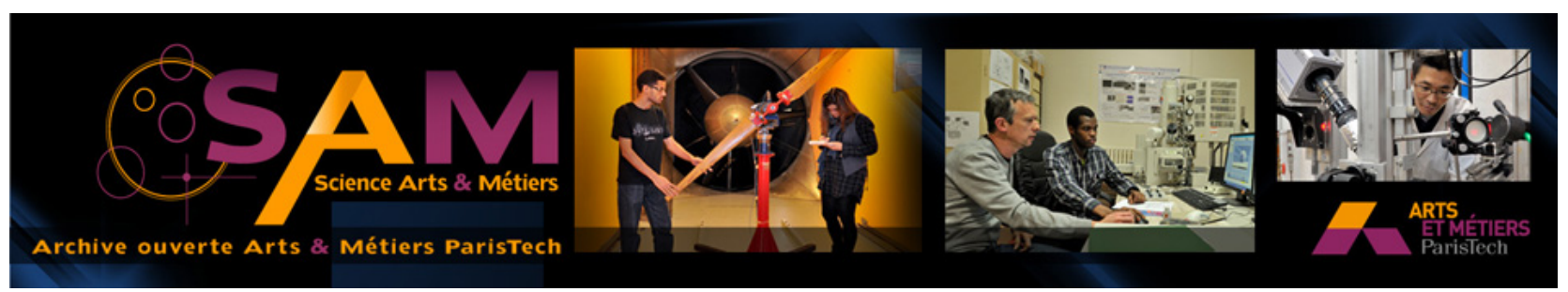

\section{Science Arts \& Métiers (SAM)}

is an open access repository that collects the work of Arts et Métiers ParisTech researchers and makes it freely available over the web where possible.

This is an author-deposited version published in: http://sam.ensam.eu

Handle ID: .http://hdl.handle.net/10985/9861

\section{To cite this version :}

Laure ARBENZ, Abdelkader BENABOU, Stéphane CLENET, Jean claude MIPO, Pierre FAVEROLLE - Characterization of the local Electrical Properties of Electrical Machine Parts with non-Trivial Geometry - International Journal of Applied Electromagnetics and Mechanics, - Vol. $48, n^{\circ} 2 \& 3$, p.201-206 - 2015 


\section{Characterization of the local}

\section{Electrical Properties of Electrical}

\section{Machine Parts with non-Trivial}

\section{Geometry}

Laure ARBENZ $^{\mathrm{a}, \mathrm{c}}$, Abdelkader BENABOU ${ }^{\mathrm{b}, 1}$, Stéphane CLÉNET

${ }^{\mathrm{b}}$, Jean-Claude MIPO ${ }^{\mathrm{c}}$ and Pierre FAVEROLLE ${ }^{\mathrm{c}}$

${ }^{a}$ L2EP/Arts et Métiers ParisTech - Centre de Lille, France

${ }^{\mathrm{b}}$ L2EP/Université Lille1, Bat. P2, 59655 Villeneuve d'Ascq, France

${ }^{\mathrm{c}}$ Valeo/2 rue André Charles Boulle, 94000 Créteil, France

Abstract. In electrical machines, knowing the electrical conductivity is of importance for the eddy current calculation, especially when massive iron parts are involved. Generally the conductivity is measured on samples of raw materials with simple geometries. Indeed, a simple geometry is suitable for applying an analytical approach to deduce the electrical conductivity from the measured electrical quantities. Nevertheless, when a non destructive measurement is required, the measurement of the electrical conductivity can become rather difficult on parts with complex geometry. To that end, with the help of the Finite Element Modeling approach (FEM), a strategy is developed to characterize the local electrical properties of parts with a non-trivial geometry.

Keywords: electrical conductivity, non-trivial geometry, Finite Element Modeling, experiment

${ }^{1}$ Corresponding Author: Abdelkader Benabou, L2EP/Université Lille1, Bâtiment P2 Cité Scientifique, 59655 Villeneuve d'Ascq, France; E-mail: abdelkader.benabou@univlille1.fr. 


\section{Introduction}

The performances of an energy conversion device that includes ferromagnetic materials depend highly on their magnetic and electrical properties. An important aspect for the performances of these materials is related to the manufacturing process of the magnetic core that can impact the properties of the material. In fact, these can be worsened compared to the raw material ones [1]. Moreover, during the manufacturing process, this impact is not necessarily repetitive and can also lead to a dispersion of these properties. These aspects are rarely taken into account in the design process of electrical machines, especially for the quantification of this impact on the performances. Therefore, in order to design and optimize these devices, the electrical conductivity is one of the parameters that can be required with a good accuracy. In fact, depending on the working frequency and thickness of the material, the knowledge of the electrical conductivity can be of importance for the accurate calculation of the eddy current losses. This is particularly the case when massive iron parts are involved in the design of the energy conversion device. In the classical experimental approach, the characterization techniques use a sample with a specific and simple geometry (cylinder, sheet). For ferromagnetic materials, the works related to the electrical conductivity measurement have been mainly focused on the case of sheets because of their extensive use for the manufacture of magnetic circuit of energy conversion devices [2], [3]. Besides, a simple geometry is usually required for applying an analytical approach to deduce the electrical conductivity. When a non destructive measurement is required, the measurement of electrical conductivity can become 
rather difficult on parts with complex geometry. Therefore, specific approaches should be provided in order to characterize the material of the end product. In this paper, a non destructive approach, combining the experiment and the Finite Element (FE) technique, is presented in order to determine the electrical conductivity of massive magnetic parts with a non trivial geometry. For the experimental part, the developed sensor is based on the principle of the four-point method proposed by Valdes in 1954 [4] and, for the FE simulations, the 3D electromagnetic field calculation software code_Carmel is employed. First, the experimental method is detailed with the model used to identify the electrical conductivity. Then, the proposed method is validated and illustrated using two kinds of parts of steel with non-trivial geometry.

\section{Characterization of the local electrical conductivity}

\subsection{Presentation of the approach}

The proposed sensor for the electrical conductivity measurement is based on the four-point method (figure 1) [4]. A current is imposed flowing through the outer pair of points and a voltage is measured between the inner points. Using the Ohm's law the ratio between the voltage and the current gives the resistance for the region between the inner points. But, except for few simple cases for which an analytical solution is available, it is rather difficult to extract the conductivity from the measured resistance on samples with nontrivial geometries. The proposed method consists in simulating the experimental device in order to extract the resistance (R) depending on both the conductivity $(\sigma)$ and position of the sensor on the part under test. Electrokinetic simulations are carried out with a 3D electromagnetic field simulation software from which the 
relationship $\sigma=\mathrm{f}(\mathrm{R})$ is determined for each sensor position. Finally, from the experimental resistance and sensor position, the adequate electrical conductivity is deduced (figure 2). As illustration, the simulated current density magnitude distribution obtained for a non trivial geometry show the interest of this approach (figure 3). Indeed, this density is far from being uniform and difficult to calculate analytically with regard to the complex geometry of the part.

\subsection{Experimental procedure}

The sensor is made of four aligned needles mounted on springs attached to a PEEK polymer (polyetheretherketone) support. These needles are connected to a micro-ohmmeter. The sensor is fixed to a motored device that allows positioning the needles adequately on the sample under test (figure 4). The positioning device, the sensor and the sample are placed in a measuring chamber to control the temperature of the environment. Indeed, to achieve the desired accuracy (typically $\pm 0.3 \mathrm{MS} / \mathrm{m}$ ), it is crucial to control the temperature of the environment. In figure 5, a test has been carried out on a sample of massive steel in order to evaluate the impact of the temperature.

\subsection{Finite element model}

The model is based on the solution of the electrokinetic problem solved by the finite element method using the scalar potential formulation. For different values of the electrical conductivity and positions of the sensor, the DC current flowing through the external needles of the sensor is imposed and the resulting voltage between the internal needles is calculated using the method presented in [5] which is very accurate. The studied domain corresponds to a rotor claw. The discretization of the domain leads to a mesh of 210000 
nodes and 1200000 tetrahedral elements. Moreover, according to the results given by the FE model, the spaces between the four needles have been optimized. In fact, the measure must be local as much as possible but the signal must be sufficiently high to be measured with the micro-ohmmeter. So, a compromise, depending on the studied sample geometry, has to be found for the spaces between the needles. In the F.E. model, the electrical conductivity has been fixed to a value close to the expected experimental conductivity. Then, a simulation has been performed with different needles spaces (figure 6). The choice has been made for the parameters $\mathrm{s}=\mathrm{a}=6 \mathrm{~mm}$.

\subsection{Validation of the procedure}

Once the optimal sensor has been defined for our application, the validation of the proposed method has been carried out in two steps. First, the procedure is applied to a reference sample with a complex geometry (figure 7). Then a simple geometry, a cylinder, is extracted from this sample. Measurement of the resistance of this cylinder is performed with the same sensor but the conductivity is obtained by the conventional analytical calculation. The testing procedure is made for three different samples. It is found that the conductivity measured for all samples are very close to the one obtained by the proposed method involving electromagnetic field calculation (table 1).

\section{Application of the approach to a forged claw pole}

The proposed method is used to compare two electrical machine parts made of forged ferromagnetic steel. Both parts have the same steel grade but have been made up with different processes of fabrication. The geometry of this part is illustrated in figure 7. For each sample, 3 acquisitions of the resistance, each one during 500s, 
are performed. Results are reported in figure 8 . The transient state is because of the zeroing process of the micro-ohmmeter. After 100s, the measure is perfectly stable and the observed difference between the 3 measurements (for the same sample) is lower than $1 \%$. Considering the observed gap between both samples, this measurement accuracy is acceptable for a comparison purpose. In fact, despite the same grade of steel, the deduced conductivities are rather different (20\%) between both samples. The observed difference is significant and higher than the measurement error.

\section{Conclusion}

When non-destructive testing is required for the electrical conductivity measurement, the usual approach, based on specific sample geometries, finds its limitation. The proposed approach, combining both measurement and simulation, enables to deduce the electrical conductivity of a sample with a non trivial geometry. The validation of the method has been carried out on a reference sample. Then, the procedure was applied to two claw samples of forged ferromagnetic steel, with the same grade but issued from two distinct manufacturing processes. The results show that the studied samples, with the exact same geometry, exhibit different electrical properties induced by the process of fabrication. It has been demonstrated that the proposed approach is suitable for devices requiring a nondestructive method and is well adapted for the ongoing study of the impact of the manufacturing process on the ferromagnetic steel properties. 


\section{References}

[1] R. Ramarotafika, A. Benabou, S. Clenet, J-C. Mipo, Experimental Characterization of the Iron Losses Variability in Stators of Electrical Machines, IEEE Transactions on Magnetics, Vol. 48, №4, p 1629-1632, 2012.

[2] F. M. Smits, Measurement of sheet resistivity with the four point probe, 711-718, s.l. : Bell System Technical Journal, 1958, Vol. 3

[3] Y. Lu, N. Bowler, J.R. Bowler, Y. Huang, Edge effects in four-point direct current potential drop measurements on metal plates, IOP Journal of Physics D: Applied Physics, 2009, Vol. 42.

[4] B. Valdes, Resistivity measurements on germanium for transistors, 420, s.l. :Proceedings of the I. R. E., 1954, Vol.42.

[5] T.Henneron, S.Clénet, F.Piriou, Calculation of Extra Copper Losses with Imposed Current Magnetodynamic Formulations, IEEE Transactions on Magnetics, vol. 42 ,N², pp 767-780, 2006. 


\section{Tables}

\begin{tabular}{|c|c|c|c|}
\hline & & $\begin{array}{c}\text { Measured resistance } \\
\text { (First measure is taken as } \\
\text { the reference) }\end{array}$ & $\begin{array}{l}\text { Calculated conductivity } \\
\text { (First measure is taken as } \\
\text { the reference) }\end{array}$ \\
\hline $\begin{array}{c}\text { Claw } \\
\text { (first } \\
\text { measurement) }\end{array}$ & $\begin{array}{l}\text { Claw 1 } \\
\text { Claw } 2 \\
\text { Claw } 3\end{array}$ & $\begin{array}{c}\mathbf{1} \\
1.030 \\
1.004\end{array}$ & $\begin{array}{c}\mathbf{1} \\
0.971 \\
0.996\end{array}$ \\
\hline $\begin{array}{c}\text { Claw } \\
\text { (second } \\
\text { measurement) }\end{array}$ & $\begin{array}{l}\text { Claw1 } \\
\text { Claw } 2 \\
\text { Claw } 3\end{array}$ & $\begin{array}{l}1.020 \\
1.019 \\
0.992\end{array}$ & $\begin{array}{l}0.981 \\
0.981 \\
1.008\end{array}$ \\
\hline $\begin{array}{c}\text { Cylinder } \\
\text { (first } \\
\text { measurement) }\end{array}$ & $\begin{array}{l}\text { Cylinder } 1 \\
\text { Cylinder } 2 \\
\text { Cylinder } 3\end{array}$ & $\begin{array}{l}5.188 \\
5.208 \\
5.206\end{array}$ & $\begin{array}{l}1.003 \\
0.999 \\
1.000\end{array}$ \\
\hline $\begin{array}{c}\text { Cylinder } \\
\text { (second } \\
\text { measurement) }\end{array}$ & $\begin{array}{l}\text { Cylinder } 1 \\
\text { Cylinder } 2 \\
\text { Cylinder } 3\end{array}$ & $\begin{array}{l}5.269 \\
5.278 \\
5.265\end{array}$ & $\begin{array}{l}0.988 \\
0.986 \\
0.989\end{array}$ \\
\hline
\end{tabular}

Table 1. Experimental results with the first measure as reference.

\section{Figure captions}

Fig. 1. Geometry of the four point sensor

Fig. 2. Illustration of the proposed approach

Fig. 3. Current density distribution

Fig. 4. Schematic drawing of the experimental device

Fig. 5. Average resistance versus temperature of the environment and geometry of the sample

Fig. 6. Simulated resistance versus needles spaces (optimization of the sensor)

Fig. 7. Geometry of the samples.

Fig. 8. Experimental results (resistance versus time) 
Figures

Fig. 1

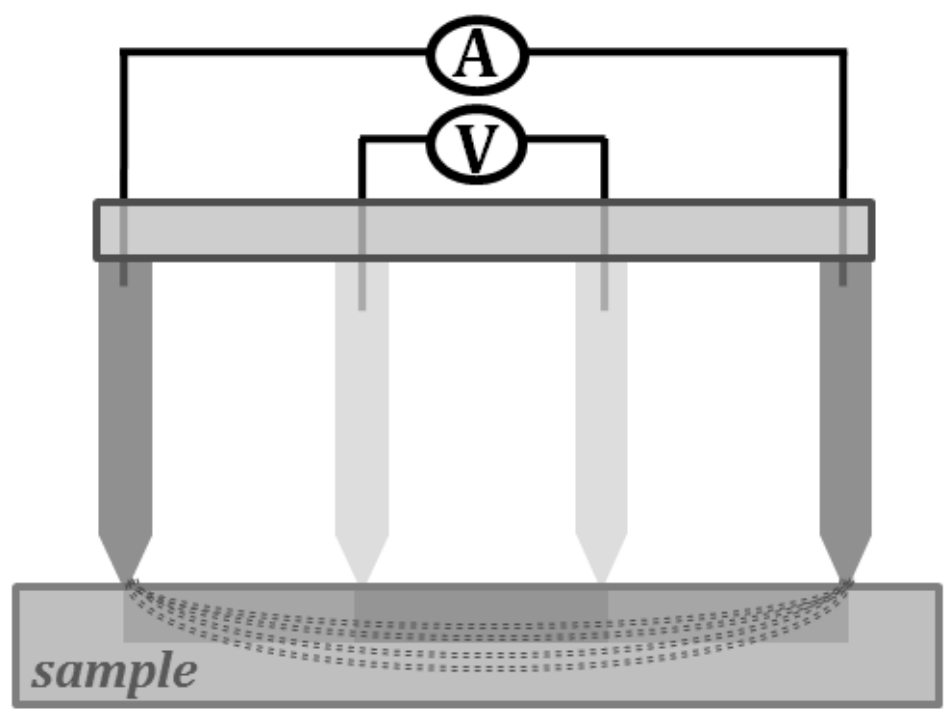


Fig. 2.

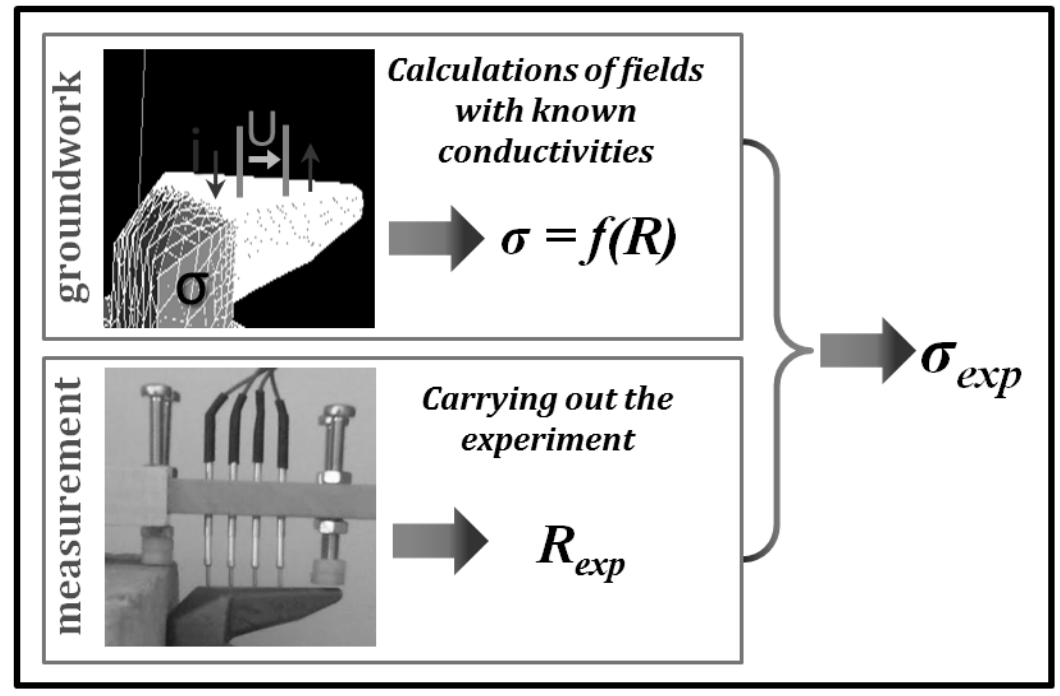


Fig. 3.

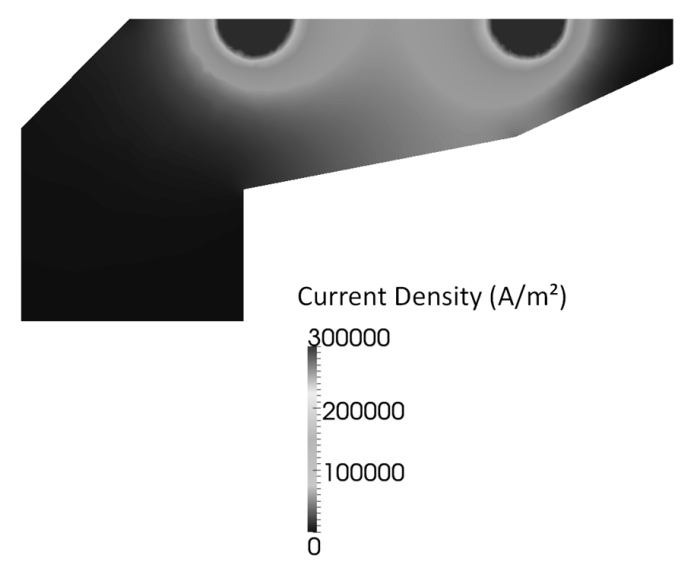


Fig. 4.

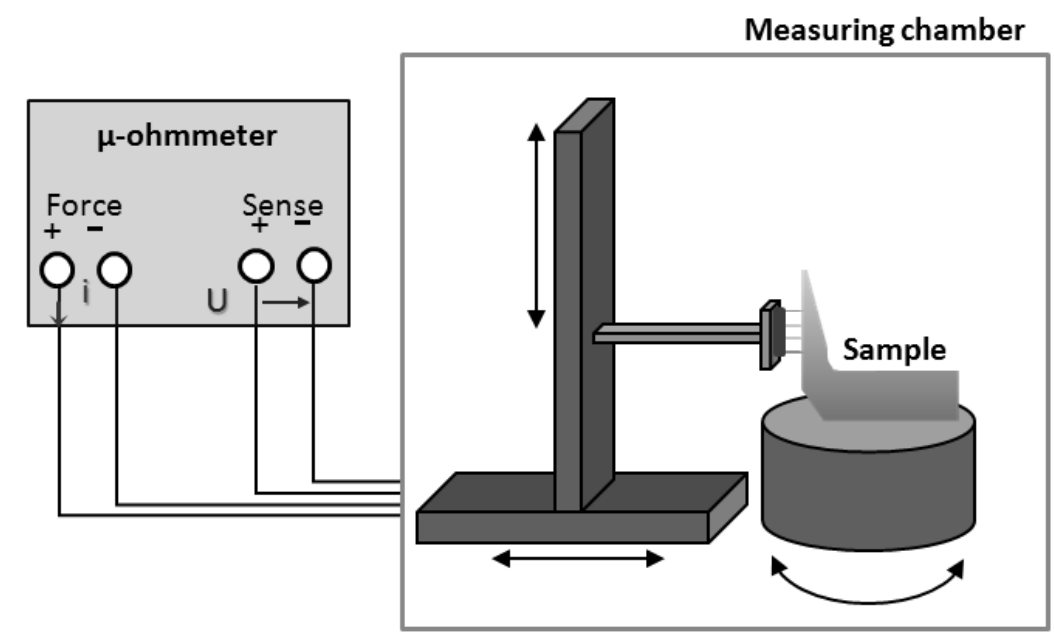


Fig. 5.
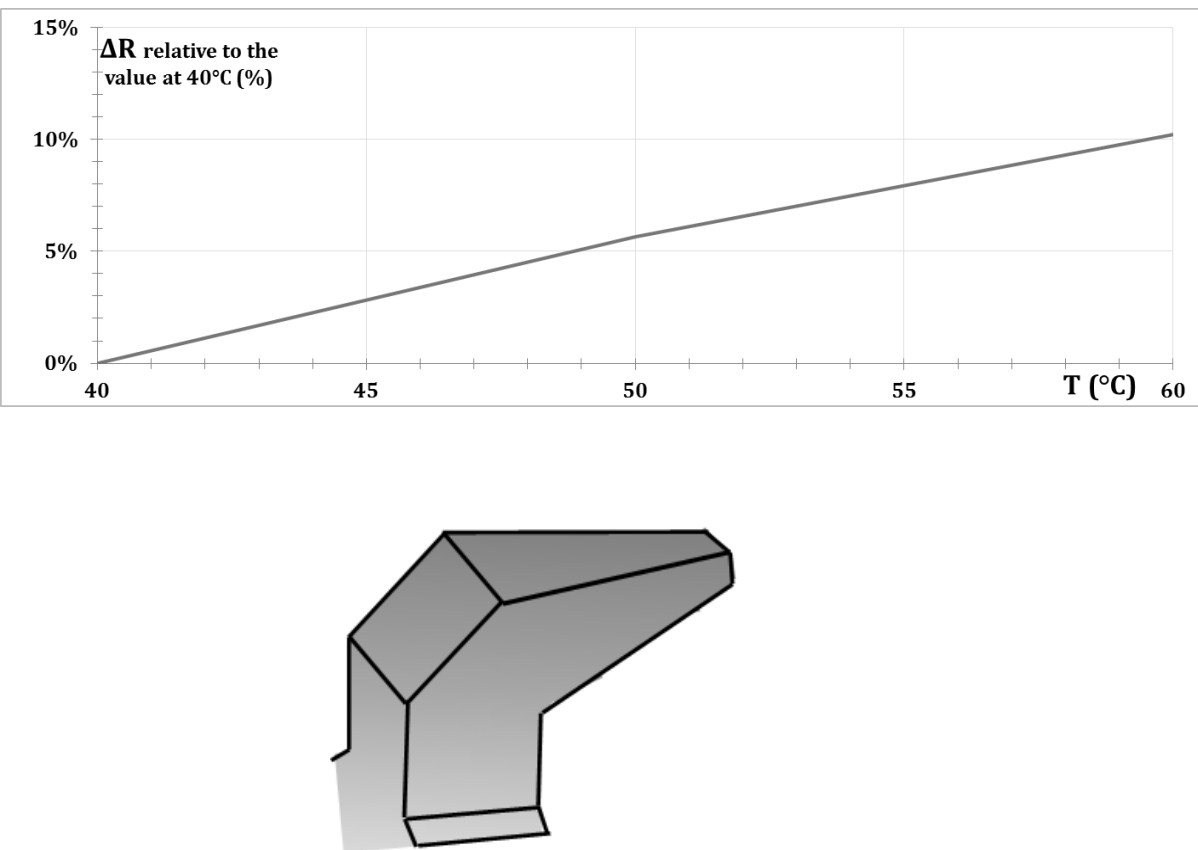
Fig. 6.
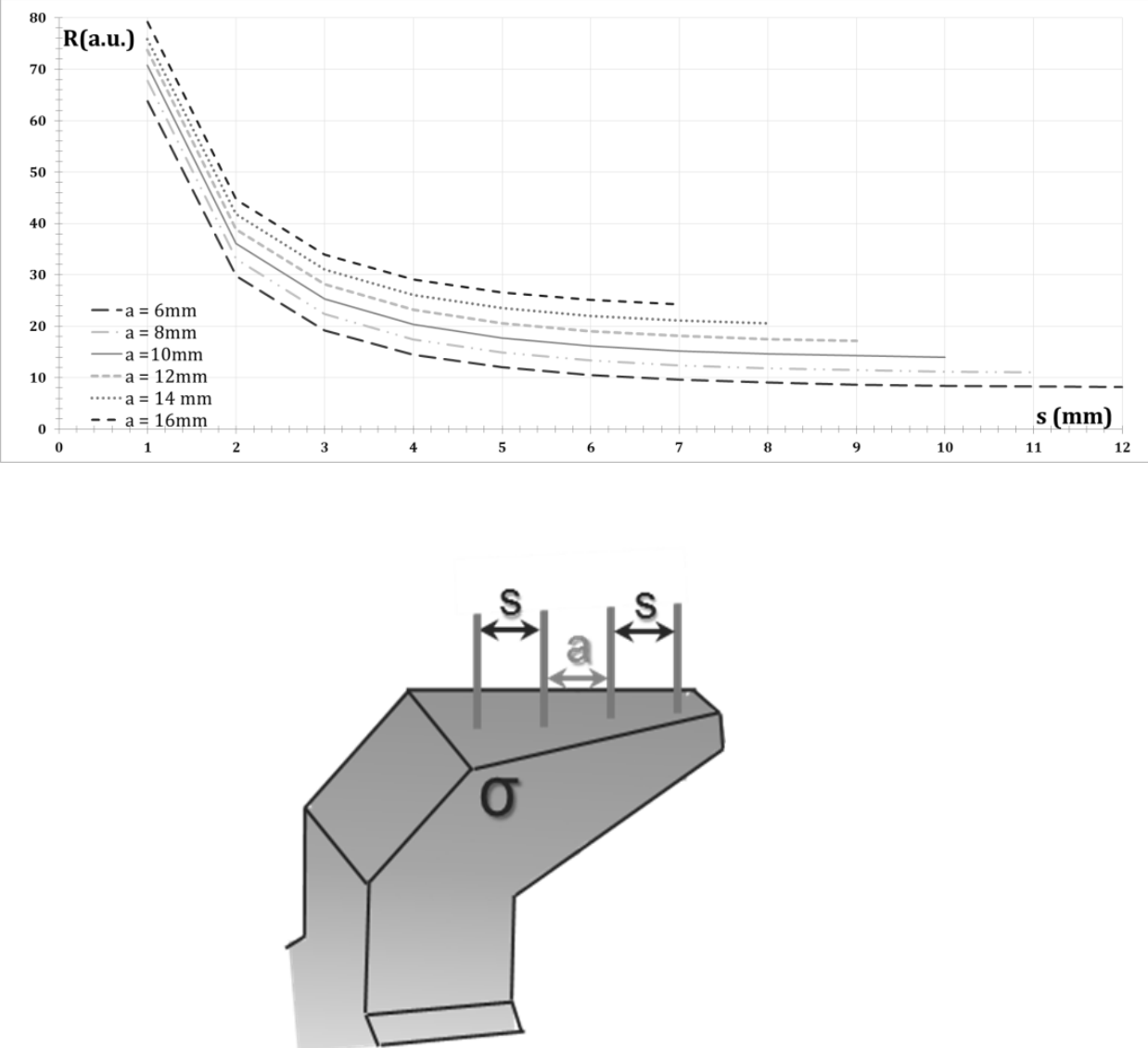
Fig. 7.

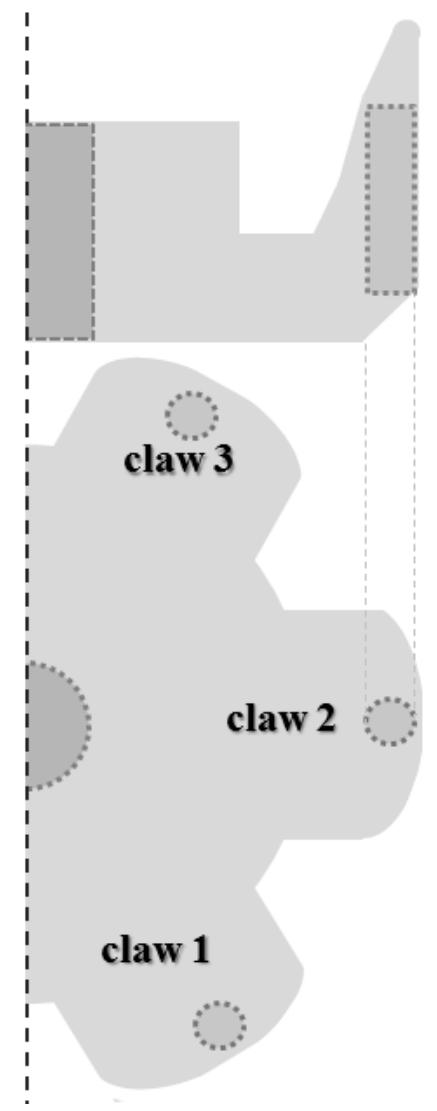


Fig. 8.

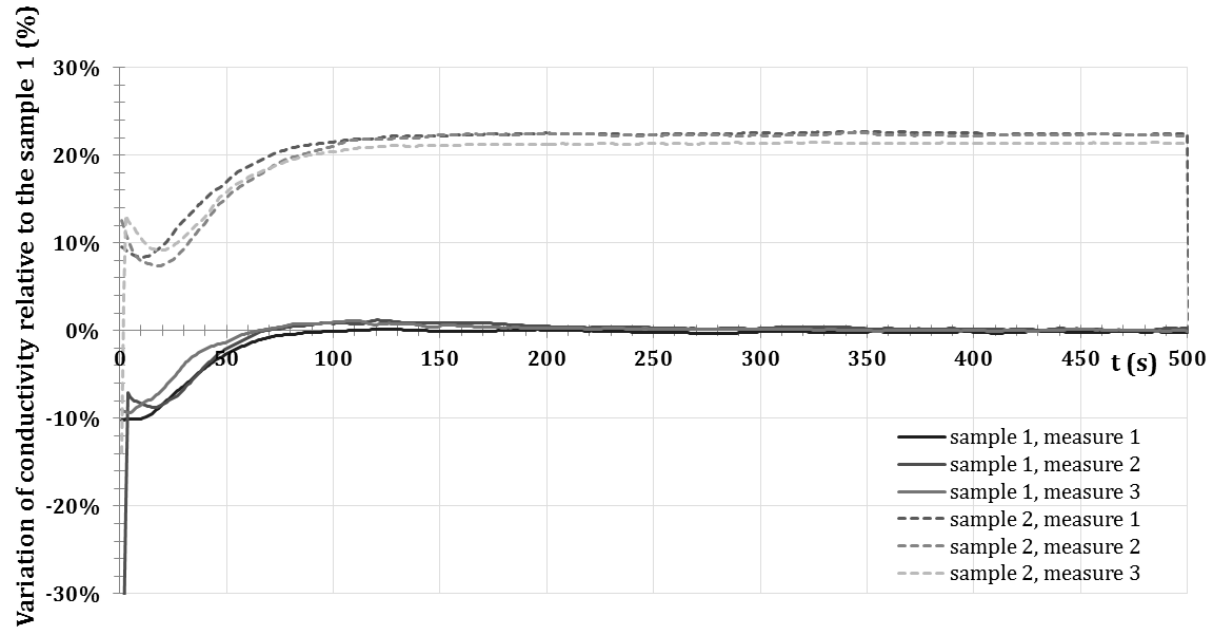

